respect to speeding throughput and diminishing work in progress by the design of equipment to give appropriate physical treatment to the goods in work. At the same time physies has also given important guidance with respect to necessary test performance requisite in materials for some of the newer methods of shoe manufacture.

All these combine to enhance productivity and improve the quality of the product: as illustration, figures for a group of firms in the Association's membership covering 80,000 workpeople show 30 per cent productivity increase over the past ten yoars in pairages per employee.

Improvement in the product is for the public good. Special illustrations of the Association's work are to be found in children's shoes, in industrial footwear, including safety boots and shoes, in H.M. Services footwear and in special footwear for expeditions (for example, high-altitude Everest boot, and boots worn in Antarctica in the Geophysical Year).

The Association's work on children's footwear, started soon after the close of the Second World War, has spread throughout the United Kingdom and has its impact on health authorities, school authorities, clinies and welfare work of all kinds throughout the whole country and the Satra Approved Last Scheme operates everywhere. The Association operates the 'Kite' mark scheme on safety boots and shoes with the British Standards Institution. Work on service footwear is done on contracts with the War Office and with the Royal Air Force.

The earliest crafts came into being to meet the primary needs of human life for food, clothing and shelter, and footwear was in at the beginning. The essential purposes are health, comfort, protection and esthetic satisfaction. Basic science of boots and shoes therefore contains a 'bio' element-biomechanics, bio-physics, physiology and anthropometry. The work at Satra House in this basic field continues, but admittedly with fluctuating intensity. It is restricted by more urgent demands from other directions and also by problems of staff recruitment. The importance of this basic work and the need to extend belief in it throughout the industry and also through to the public is a constant spur to further effort.
H. BR.ADLEY

\title{
SEAWEED TECHNOLOGY
}

$\mathrm{T}$ HE fourth International Seaweed Symposium was held at Biarritz, during September 18-25, and was attended by more than 220 scientists and industrialists from thirty-four countries. In his opening address, Prof. Maurice Fontaine, directeur de l'Institut Oceanographique, extended a cordial welcome to the delegates.

At the opening session, the inaugural address was given by Dr. E. E. Percival (Scotland), who compared the polysaccharides synthesized by marine algae with those of the higher plants. Whereas many similarities between the two exist, the major difference lies in the fact that all seaweeds synthesize at least one polysaccharide containing ester sulphate groups. The brown seaweed polysaccharides, alginic acid, focoidin, and laminarin have few similarities with those of other groups of plants. The red algae synthesize mainly 1,3-linked galactans, a tendency also shown by the higher plants; but there the resemblance ends. The algal polymers also contain varying proportions of 1,4-linked 3,6-anhydro-Dand -L-galactose and sulphate groups. Starch-type polysaccharides, xylans and mannans have been isolated from different species of red and green weeds. Laminarin-type molecules have also been detected in the green algae. The major polysaccharides of these latter weeds, however, appear to fall into two groups which closely resemble, except for the presence of ester sulphate, either the plant gums or the hemicelluloses of land plants. Dr. Percival emphasized, however, that structural studies in this vast field of natural products, particularly in the Chlorophyceae, are still in their infancy, and it is probable that many differences in the fine structure of these complex molecules will emerge on further investigations. Dr. L. Provasoli (United States) reviewed recent progress in the culture of bacteria-free marine algae.

The various interests in algology, algal chemistry and seaweed utilization were all evident at this Symposium, but, in contrast with previous symposia, the botanical section was unusually well represented. In fact, almost two-thirds of the papers presented were on taxonomy and the culture of algae or their distribution, while the other papers were almost equally divided between pure chemistry and the various facets of the industrial utilization of seaweeds.

Critical observations on the taxonomy, growth and ecology of the marine algae ranged from a paper by Dr. P. S. Dixon (England), which suggested the disposition of the carpogonium might prove valuable in the sub-division of the Florideae, to Dr. W. J. North's (United States) account of the successful transplantation of Macrocystis pyrifera, which in cluded a detailed account of the successful establish ment in the ocean of plants raised from spores in the laboratory. Other investigations on the photosynthesis, physiology and growth of $M$. pyrifera by Dr. K. A. Glendinning (United States) suggest that this commercially important alga is perhaps the most widely studied of all the algae.

The genus Porphyra is also widely studied by both botanists and chemists. Dr. E. Conway (Scotland), in an account of her work on the growth and reproduction of $P$. linearis and $P$. umbilicalis, directed attention to the similarities and differences in the reproduction of these algae, and Dr. T. Fujiware (Japan) reported on her chemical investigation of the water-soluble red pigment, phycoerythrin, from the alga $P$. tenera. A further account of the sugar sulphates isolated from the mucilage of $P$. umbilicalis was given by Dr. J. R. Turvey (Wales). The predominant unit containing sulphate is L-galactose-6. sulphate, but several disaccharide sulphates have now been obtained and separated and two types of sulphate ester have been isolated. In each case the sulphate was attached at carbon (6) of an $x$-galactose residue, but one group contained $\mathrm{D}$-galactose and the other 6-O-methyl-D-galactose. In some of these compounds the sulphate ester group was attached to the reducing sugar unit, whereas in others it was attached to the non-reducing sugar unit.

The work being carried out in the Chemistry Department of the University of Edinburgh on the green algae was summarized by Dr. D. J. Manners 
and Dr. E. E. Pcreival. The former gave an account of the extraction of enzymes from Cladophora rupestris in which both amylase and maltoso activity are present. The amylase activity appears to involve random hydrolysis and diffors in other ways from B-amylase; this algal amylase has not yot heen purified. Dr. Percival stressed the similarity of the polysaccharides synthesized by both Ulva lactuca and Enteromorpha compressa from each of which she has isolated a polysaccharide containing L-rhamnose (35 per cent), n-glucuronic acid (18 per cent), ester sulphate groups ( 16 per cont) together with D-glucose and D-xylose. Evidence was presented which suggested the polysarcharide is a chain of $1-3^{\prime}$-linked rhamnose units carrying side-chains of glucuronic acid and rhamnose units linked $1,4^{\prime}$ with sulphate groups attached at the carbon (2) position of some of the rhamnose residues.

In the post-war years, a Danish seaweed industry has been developed on the extraction of the agar-like colloids of the red alga Furcellaria fastigiata, and an account of the progress of this industry was given by Dr. S. Lund (Denmark), while Dr. K. Czapke (Poland) described the extraction of the colloid and its chemical and physical properties. An interesting commorcial point of view was expressed in a paper from Mr. H. C. Peterson (United States), who suggested areas where there is scope for closer co-oper ation between purely chemical research, botanical investigations, soawoed producers and sellers of these new seaweed extracts.

The brown algae are widely studied, partly because of their commercial importance but also because of thoir abundance and general availability. Dr. E. Burrows (England) outlined the ecological factors associated with the genus Fucus, and Dr. B. Moss (England) gave an account of the regeneration of damaged thallus of $F$. vesiculosis, showing that the now growth is always similar to the cellular structure at the site of damage and may be corrolated with the auxin concentration there. Variations in the chemical composition of the Fucaceae represent a well-known problem. These variations are both seasonal and local. Miss I. Munda (Yugoslavia) showed that local variations can be attributed to decreased photosynthetic activity in areas of decreased salinity, a factor which also brought about earlior ripening of the receptacles. Transplantation of the plants to areas of different salinity confirmed these results and also showed the uptake of divalent ions incroased with decreasing salinity. Dr. J. Kain (England), in an examination of Laminaria hyperborea showed that plants of the same age are smaller at greater depths, which indicates the effect of diminishing light intensity on growth-rate. Mr. F. Baardseth (Norway) described how the distribution, size and types of the various cell-types, physodes, wall structures, etc., coupled with staining and other microscopic techniques, can be used to identify the constituent brown algao in samples of ground seaweed-meal. Among the chemical work on the brown alga must be mentioned Mr. Jensen's (Norway) papor on the estimation of ascorbic acid in algae, and the paper by $\mathrm{Mr}$. A. Haug (Norway) on the polvsaccharides extracted from Ascophyllum nodosum by aqueous sodium carbonate, who showed the prosenes of simplo monosaccharides and sulphatod polysaccharides. An up-to-date reviow of present-day work on the constitution of laminarin by Dr. ' $T$. Dillon (Eiro) suggested that there is still no universal agroement on the constitution of the laminaring and gave an outline of present structural work in his laboratory. Despite the commercial importance of alginic acid and the recent publications on its structure, only two papers on alginic acid were read at the Symposium. In an account of resourch now boing carried out in Norway, Mr. Haug detriled the application of chromatographic and electrophoretic methods of separating uronic acids to alginic acid and, from the metallic ealts and equivalent of the acid, described a simple way to estimate the uronic acid composition of alginates. In the other paper Mr. Massoni (France) discussed the viscosity of solutions of alginates.

The geographical distribution of seaweeds and descriptions of regional flora were given in a series of papers, such as those describing the flora of northwest Greenland (Dr. R. T. Wilce, United States) and of Patagonia (Mr. O. Keshnomann, Argentine). Several authors spoke on European algae, and Dr. C. I. Macfarlane (Canada) deserves special mention for the excellence of her slides showing the algae of Nova Scotia and the associated seaweed industry, which now harvests 3,500,000 lb. of Chondrus crispus annually. The outstanding features in this section, however, were on the mapping and mensuration of seaweeds. Prof. Ad. D. de Virville (France) detailed a scheme for mapping the algae designed to show, by conventional signs, the extent and typo of algal flora. Such a map would bo useful not only to botanists but also to marine zoologists, fishing interests and commercial interests in seaweed. The estimation of the total woight of seaweed in an area. is of great commercial importance, and Mr. B. Grenager (Norway) described the application to seaweed surveys of a modified form of strip survey used in forestry. A theoretical model of coast gave mean values in good accord with mean values actually found in field work.

The culture of marine algae is an important field where work has contributed to our knowledge of the nutritional requiroments of the algae and has given methods of growing pure cultures and provided material for the isolation of metabolic products. Work in this field has been the speciality of a few workers, and Dr. Provasoli (United States, with Dr. H. Iwasaki, Japan) described notable advances in techniques which allow the culture of multi-cellular algae. A technique of antibiotic treatment, coupled with physical methods, such as repeated immersion of small pieces of the alga in agar, which possibly removes bacteria and fungi by friction, has enabled a number of red and green algae to be grown in bacteria-free culture. Artificial sea-water is satisfactory for most species, but Ulva spp. appear to require the addition of adenine and kinetin. Mme. P. Gaynal (France) also described the culture of Ulva fasciata Del. and Dr. R. Bandrimont (France) outlined the cultural requirements for the successful germination and growth of the zoospores of Ulva spp. Prof. H. A. von Stosch (Germany), working with Asparagopsin armata, showed that the iodine requiroment of this alga is equally satisfied with olementary iodino, iodide, iodate, periodato or diiodotyrosine, and presented evidence to show that arsenic, as arsenate, may interfere with the utilization of phosphate. One interesting facet of algal chemistry which has doveloped from cnlturo work was described by Ur. J. A. Mowat (Scotland), who has demonstrated auxins and gibberellins in extracts of marine phytoplankton and cultures of marine unicellular algne. Several unidentified indolo compounds aro present in the oxtracts and the gibberellin-like substances differ from the gibberellins so far known in the higher 
plants. The larger algae, such as Laminaria digitata, L. hyperborea and Ascophyllum nodosum, have also been shown to contain similar auxins but in smaller proportions than in the unicellular algae.

In the session on the industrial utilization of seaweeds, Dr. C. Anderson (Germany) discussed the physical chemistry of mixtures of cocoa and carrageenin which are commonly used in the manufacture of chocolate drinks. The use of seaweed as a manure, while traditional in some maritime districts, has received little scientific attention, and two papers on this subject suggest seaweed is a valuable manure. Mr. Myklestad reported that work in Norway during the past three years has shown that seaweed has considerable manurial value on certain types of soil. Dr. R. F. Milton (England) described a commercial process, using alkaline hydrolysis under pressure, for the manufacture of a liquid seaweed product. It was said that about 95 per cent of the seaweed could be dissolved by this method and chemical and fertilizer studies were recorcled. Mr. E. Booth (Scotland) gave an account of the trace elements in seaweed and their importance in feeding. stuffs and fertilizers, and Mr. Hallson (Iceland) traced the history of the use of seaweed as a feedingstuff in Icoland over the past 1,000 years from a number of authentic sources.

There was only a limited time available for discussion on each paper, but ample opportunity for private discussion was provided at the several seaweed collecting excursions and the various social functions held in connexion with the symposium. It was decided to publish the proceedings of the symposium and a résumé of the discussions ; it is expected that the complete text will be available shortly. It was agreed that the next symposium would be held in Halifax, Nova Scotia, in 1964. The International Advisory Committee, consistine of Prof T. Braarud (Norway), Prof. T. Dillon (Eire), Prof. J. Feldman (France), Mr. O. Rodriguez (Spain), Prof. Ad. D. de Virville (France), Dr. F. N. Woodward (Scotland) and Dr. E. G. Young (Canada), has invited Prof. C. Araki (Japan) and Prof. T. Levring (Sweden) to join the Committee, and will assist the Canadian National Committeo with the next symposium, and collaborate with the International Phycological Society in the organization of a concurrent meeting in Halifax.

E. Boorn

\title{
GAS-LIQUID CHROMATOGRAPHY-VARIATIONS IN PARTITION COEFFICIENTS WITH CARRIER GAS
}

\author{
By A. GOLDUP, G. R. LUCKHURST and W. T. SWANTON \\ The British Petroleum Company Limited, Petroleum Division, Research Centre, \\ Sunbury-on-Thames, Middlesex
}

$\mathrm{R}^{\mathrm{s}}$ ECENTLY, while carrying out an analysis of the gasoline fraction of a crude petroleum ${ }^{1}$, it was observed that the degree of separation attained for some hydrocarbons was remarkably improved, and for others severely impaired, when the carrier gas was changed from nitrogen to hydrogen. In the $\mathrm{C}_{7}$ fraction, for example, methylcyclopentane and 2,2 . dimethylpentane, unresolved in nitrogen, were partially separated in hydrogen, whereas the separation factors of 2,4-dimethylpentane and benzene, 3,3-dimethylpentane and cyclohexane were found to be smaller in hydrogen than in nitrogon. A comparison of the two chromatograms in this region is shown in Fig. 1. Since the separation factor is independent of column resolution and a function only of temperature for the same stationary phase, these variations must be due to changes in the partition coefficients.

These earlier results have now been confirmed and similar effects observed with other carrier gases. The apparatus used was similar to that already described ${ }^{1}$ but incorporated a glass capillary column $300 \mathrm{ft}$. long with an internal diameter of 0.005 in., coated with a film of squalano about $0 \cdot 13 \mu$ thick. The column was thermostatically controlled at $25^{\circ} \mathrm{C}$. to within $\pm 0.01^{\circ} \mathrm{C}$. and the carrier gas purified with a trap of activated $5 \mathrm{~A}$ Linde molecular sieve. The $k^{\prime}$ factor (the ratio of liquid phase capacity to gas phase capacity) which is directly proportional to the partition coefficient was measured for a number of hydrocarbons in the carrier gases, hydrogen, nitrogen, helium, argon and carbon dioxide. Throughout the investigation the column inlet pressure (and hence the average column pressure) was maintained constant. With this apparatus tho repeatability of the $k^{\prime}$ factor determination was better than \pm 0.3 per cent. The results obtained are shown in Table 1 .

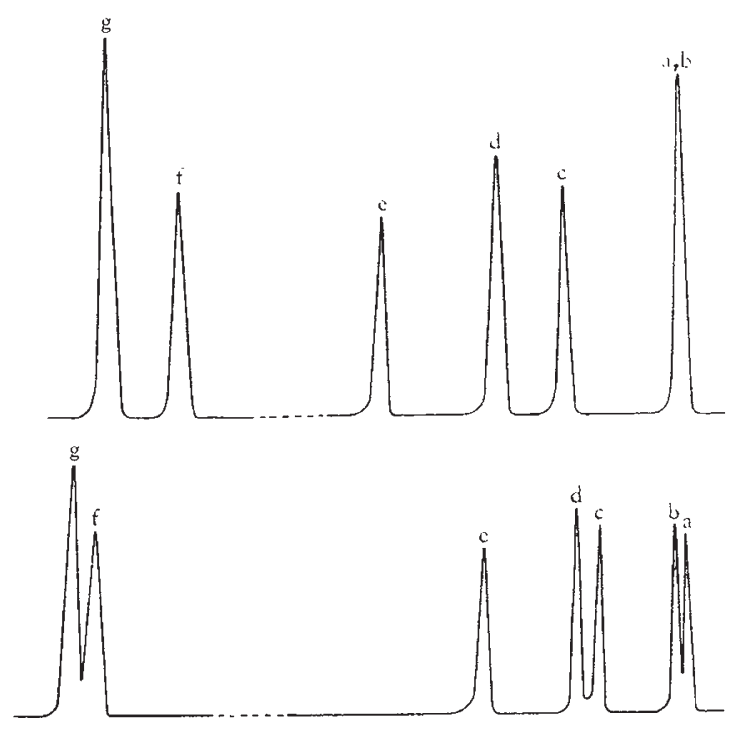

Fig. 1. Variations in the degree of separation of seven hydrocarbons using (above) nitrogen and (below) hydrogen. $900 \mathrm{ft}$. temp., $25 \cdot 0^{\circ} \mathrm{C}$.; gas inlet pressure, $153 \mathrm{lb} . / \mathrm{in}^{2}$ : detector, flame ionization. $a$, Methylcyclopentane; $b, 2,2$-dimethylpentane $c, 2,4$-dimethylpentane; $d$, benzene; $e, 2,2,3$-trimethylbutane $f$, 3,3-dimethylpentane; $g$, cycluhexane 